\title{
PECULIARITIES OF CARRYING OUT OF PHACOEMULSIFICATION IN LITTLE DISLOCATION OF THE CRYSTALLINE LENS AND WEAKNESS LIGAMENTS OF ZINN
}

\section{Bakbardina L.M., Tutchenko N.N., Bakbardina I.I \\ Ophthalmology Clinic Eye Microsurgery Center}

Was been present result of treatment 62 patients with weaknesses ligaments of Zinn and small sublucsations of lens. Authors proposed method of standartization of the diagnostics, treatment and operations tactics in this category of patientis.

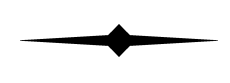

УДК 617.7-007.681+617.741-004.1-089.168

\section{СОВРЕМЕННЫЕ ВОЗМОЖНОСТИ “АВ INTERNO» ТРАБЕКУЛЭКТОМИИ С ИСПОЛЬЗОВАНИЕМ ОПЕРАЦИОННОЙ СИСТЕМЫ “ТRАВЕСТОМЕ» У БОЛЬНЫХ ПЕРВИЧНОЙ ОТКРЫТОУГОЛЬНОЙ ГЛАУКОМОЙ И КАТАРАКТОЙ}

\author{
С. К. Дмитриев, д-р мед. наук, Т. В. Душенчук, мл. науч. сотр., Ю. М. Лазарь, врач, \\ Е. И. Кондратьева, врач
}

ГУ «Институт глазных болезней и тканевой терапии им. В. П. Филатова НАМН Украины»

\begin{abstract}
Встановлено, що «Ab interno» трабекулектомія звикористаннямопераційної системи «Trabectome» дозволяє знизити внутрішньоочний тиск у хворих первинною відкритокутовою глаукомою на 21,5\% на термін спостереження $(173 \pm 170,2)$ днів. Механізм гіпотензивної дії цього виду операції пов'язаний з мікроінвазивним видаленням трабекулярної тканини, яка є основною причиною, що перешкоджає відтоку внутрішньоочної рідини. До переваг цього методу трабекулектомії необхідно віднести можливість одномоментного проведення факоемульсифікації через єдиний тунельний розтин рогівки.
\end{abstract}

Ключевые слова: первичная открытоугольная глаукома, катаракта, трабекулэктомия, внутриглазное давление.

Ключові слова: первинна відкритокутова глаукома, катаракта, трабекулектомія, внутрішньоочний тиск.

Введение. Первичная открытоугольная глаукома (ПОУГ) и катаракта являются часто встречающейся сочетанной патологией, которая, по данным различных авторов, может наблюдаться в $17-76 \%$ случаев [1]. Причем у больных ПОУГ старше 50 лет катаракта встречается в три раза чаще, чем в группе пациентов без глаукомы [16]. Известно, что глаукома и катаракта являются основной причиной слепоты и инвалидности в структуре офтальмологической патологии [5, 17], поэтому усовершенствование методов лечения данной категории больных является чрезвычайно важной задачей.

Несмотря на значительный прогресс в технологии оперативного лечения как глаукомы, так и катаракты, до сих пор продолжается обсуждение по поводу оптимальной хирургической тактики лечения больных с данным видом сочетанной патологии [2, 3, 4]. Существующие подходы к лечению больных ПОУГ и катарактой разнообразны и зависят от стадии заболевания, уровня внутриглазного давления, компенсации глаукомного процесса [20]. В практике часто используется принцип поэтапной хирургии, когда одно из оперативных вмешательств (факоэмульсификация или антиглаукомная опе- рация) выполняется на начальном этапе лечения. При этом учитывают гипотензивный эффект, который может следовать после удаления хрусталика методом факоэмульсификации и проявляется в снижении внутриглазного давления (ВГД) на 2-4 мм рт.ст. в отдаленном послеоперационном периоде [12].

Большинство авторов считает $[11,13]$, что трабекулэктомия является стандартной операцией для снижения ВГД, которая обеспечивает его нормализацию на протяжении длительного времени после хирургического вмешательства. В современной офтальмологии трабекулэктомия часто выполняется в сочетании с факоэмульсификацией с интраоперационным применением антиметаболита митомицина С. Применение митомицина С при комбинированных операциях улучшает послеоперационное функционирование созданной зоны фильтрации и способствует эффективному снижению ВГД [15]. Однако применение митомицина С может сопровождаться развитием внутриглазной

(C) С. К. Дмитриев, Т. В. Душенчук, Ю. М. Лазарь, Е. И. Кондратьева, 2012 
гипотонии, кровоизлияний, увеита, а также в ряде случаев -эндофтальмита $[6,9,18,19]$.

Вместе с тем в современной литературе описаны другие методики антиглаукоматозных операций, например, эндоскопическая циклофотокоагуляция, «ab interno ELT» (эксимер-лазерная трабекулотомия), шунтрирование с «SOLX Gold Shunt» и «ExPRESS GFD», непроникающая глубокая склерэктомия с вискоканалостомией, круговая вискодилятация и растяжение Шлеммового канала микрокатетером и «ab interno» трабекулэктомия с использованием операционной системы «Trabectome» [8].

Методика «ab interno» трабекулэктомии с использованием операционной системы «Trabectome» описана во многих статьях [10, 14], в том числе с приведением гистологических изменений в глазу после ее применения. В 2004 году эта операция была одобрена FDA для внедрения в практическую офтальмологию и используется в США и во многих странах мира. Методика «ab interno» трабекулэктомии с использованием системы «Trabectome» применяется как самостоятельная операция или в сочетании с факоэмульсификацией. К преимуществу данного способа хирургического лечения относят сохранение целостности конъюнктивы и склеры, которые при традиционной методике трабекулэктомии подвергаются операционной травме, воспалению и рубцеванию.

Цель исследования - изучить динамику внутриглазного давления у больных ПОУГ после проведения «ab interno» трабекулэктомии с использованием системы «Trabectome».

МАТЕРИАЛ И МЕТОДЫ. Операционная система «Trabectome» («NeoMedix Inc.», CША) предназначена для минимально инвазивного хирургического лечения больных ПОУГ путем удаления (абляции) трабекулярной сети протяженностью 90-120 при помощи электрического разряда под микроскопическим контролем. При проведении данной методики применяется одноразовая рукоятка системы «Trabectome» $(19,5 \mathrm{G})$, посредством которой производят абляцию трабекулярной ткани с одновременной аспирацией и ирригацией.

Все больные были прооперированы по стандартной схеме. Туннельный разрез роговицы шириной 1,7 мм был произведен в височном квадранте, в переднюю камеру введена гидроксипропил метилцеллюлоза. Затем в переднюю камеру вводили иглу одноразовой рукоятки системы «Trabectome» и устанавливали на роговицу операционную гониолинзу Swann-Jacobs. Под микроскопическим контролем в Шлеммов канал вводилась операционная игла, при помощи которой производили абляцию трабекулярной ткани на протяжении 60-120 разряда 0,7- 0,8 W, при одновременной аспирации со скоростью 10 мл/мин. В конце операции из передней камеры в полном объеме удалялся вискоэластик.

ФЭ проводилась по общепринятой методике на факомашине «Infiniti ® Vision System» («Alcon») через ранее произведенный туннельный разрез. Все больные в послеоперационном периоде получали местно инстилляции антибактериальных и противовоспалительных препаратов.
Уровень ВГД в послеоперационном периоде определялся с использованием тонометра Маклакова через 1 неделю, 2 недели, 3-5 недель, 6-8 недель, 9-12, 13-26, 27 и больше недель после операции.

Под наблюдением находились 52 больных (63 глаза) первичной открытоугольной глаукомой, которым была выполнена антиглаукомная операция «ab interno» трабекулэктомия с использованием операционной системы «Trabectome», из них 19 мужчин и 33 женщины в возрасте от 32 до 85 лет (средний возраст $(67,6 \pm 11,0)$ лет). На 25 глазах наблюдались клинические признаки псевдоэксфолиативного синдрома. На 5 глазах предварительно проводилась ФЭ с имплантацией ИОЛ, на одном глазу -витреоретинальное вмешательство по поводу регматогенной отслойки сетчатки (табл.1).

Таблица 1

Общая характеристика больных

\begin{tabular}{|c|c|}
\hline Изучаемый показатель & Значение \\
\hline Общее количество больных & 52 \\
\hline Количество глаз & 63 \\
\hline \multicolumn{2}{|l|}{ Возраст } \\
\hline Средний & 67,6 лет \\
\hline SD & 11,0 лет \\
\hline Минимум & 32 года \\
\hline Максимум & 85 лет \\
\hline \multicolumn{2}{|l|}{ Пол } \\
\hline Мужчины & 19 \\
\hline Женщины & 33 \\
\hline \multicolumn{2}{|l|}{ Глаз } \\
\hline $\mathrm{OD}$ & 33 \\
\hline $\mathrm{OS}$ & 30 \\
\hline \multicolumn{2}{|l|}{ Сопутствующая патология } \\
\hline ПЭС & 25 \\
\hline ВМД & 2 \\
\hline Увеит & 1 \\
\hline ПДРП & 1 \\
\hline \multicolumn{2}{|l|}{ Острота зрения до операции: } \\
\hline$<0,01$ & 3 \\
\hline $0,01-0,09$ & 10 \\
\hline $0,1-0,25$ & 22 \\
\hline $0,3-1,0$ & 28 \\
\hline \multicolumn{2}{|l|}{ Стадия глаукомы: } \\
\hline Начальная & 32 \\
\hline Развитая & 19 \\
\hline Далекозашедшая & 12 \\
\hline \multicolumn{2}{|l|}{ Состояние хрусталика } \\
\hline Катаракта & 50 \\
\hline Артифакия & 13 \\
\hline \multicolumn{2}{|l|}{ Ширина угла : Shaffer grade } \\
\hline $\mathrm{I}$ & 9 \\
\hline II & 27 \\
\hline III & 9 \\
\hline IV & 18 \\
\hline \multicolumn{2}{|l|}{ Пигментация угла передней камеры } \\
\hline I & 1 \\
\hline II & 13 \\
\hline III & 22 \\
\hline IV & 27 \\
\hline \multicolumn{2}{|l|}{ Предварительно проведенные операции } \\
\hline ФЭ & 12 \\
\hline ФЭ + синусотрабекулэктомия & 1 \\
\hline Витрэктомия & 1 \\
\hline
\end{tabular}


Окончание табл. 1

\begin{tabular}{|l|c|}
\hline \multicolumn{1}{|c|}{ Изучаемый показатель } & Значение \\
\hline Повторные операции после трабекулэктомии & \\
\hline ФЭ & 3 \\
\hline ГНСЭ & 2 \\
\hline ВЭ & 1 \\
\hline Репозиция ИОЛ & 1 \\
\hline Лазерная иридотомия & 1 \\
\hline
\end{tabular}

У наблюдаемых больных на 50 глазах проводилась комбинированная операция: ФЭ с имплантацией ИОЛ и трабекулэктомия с использованием операционной системы «Trabectome», на 13 глазах - только трабекулэктомия.

До проведения операции местную гипотензивную терапию получали 22 больных (30 глаз). Из них один вид лекарственных препаратов был назначен в 21 случае, два и более (в том числе комбинированные) - в 9 случаях (табл. 2).

Таблица 2

Местная гипотензивная терапия до операции

\begin{tabular}{|l|c|}
\hline \multicolumn{1}{|c|}{ Фармакологическое действие } & $\begin{array}{c}\text { Количество } \\
\text { глаз }\end{array}$ \\
\hline$\beta$-адреноблокаторы & 16 \\
\hline М-холиностимуляторы & 1 \\
\hline Простагландины & 9 \\
\hline Агонисты $\alpha-2$-адренергичных рецепторов & 4 \\
\hline Ингибиторы карбоангидразы II & 5 \\
\hline Селективные $\beta$-1-адреноблокаторы & 3 \\
\hline
\end{tabular}

РЕЗУЛЬТАТЫ И ИХ ОБСУЖДЕНИЕ. Установлено, что применение методики «аb interno» трабекулэктомии с использованием операционной системы «Trabectome» у больных ПОУГ привело к снижению $(\mathrm{p}=0,0000001)$ ВГД на $21,5 \%$ в средние сроки наблюдения $(173 \pm 170,2)$ дней. При этом средний уровень предоперационного ВГД составил $(26,1 \pm 3,23)$ мм рт. ст., а после операции $(20,5 \pm 3,23)$ мм рт. ст.

Динамика показателей ВГД в зависимости от стадии глаукомы представлена в таблице 3, из которой следует, что при всех стадиях глаукомы отмечается достоверное снижение $(p<0,05)$ ВГД по сравнению с его предоперационным уровнем. При этом максимальное снижение ВГД на 28,7 \% (с $(28,6 \pm 7,82)$ до $(20,4 \pm 2,57)$ мм рт. ст.) отмечается в группе больных с далекозашедшей стадией открытоугольной глаукомы. При начальной стадии глаукомы уровень ВГД снизился с $(25,1 \pm 4,38)$ до $(20,3 \pm 3,39)$ мм рт. ст., а при развитой стадии с $(26,0 \pm 5,47)$ до $(21,1 \pm 3,44)$ мм рт. ст. (табл. 3$)$.

Снижение ВГД отмечалось уже через 1 неделю после проведения операции $(\mathrm{p}=0,041)$, однако именно в этот срок наблюдения выявлен наибольший разброс показателей ВГД, что связано с появлением в передней камере незначительного кровоизлияния. Гифема наблюдалась в 7,9 \% случаев (5 глаз) и, как правило, самостоятельно рассасывалась в течение 3-8 дней сопровождаясь кратковременным повышением ВГД (рис. 1, рис. 2).
Таблица 3

Показатели внутриглазного давления (мм рт. ст) после «ab interno» трабекулэктомии в зависимости от стадии глаукомы $(\mathrm{M} \pm \mathrm{SD})$

\begin{tabular}{|l|c|c|c|}
\hline \multirow{2}{*}{ Уровень ВГД } & \multicolumn{3}{|c|}{ Стадия глаукомы } \\
\cline { 1 - 4 } & начальная & развитая & $\begin{array}{c}\text { далекоза- } \\
\text { шедшая }\end{array}$ \\
\hline До операции & $25,1 \pm 4,38$ & $26,0 \pm 5,47$ & $28,6 \pm 7,82$ \\
\hline После операции & $20,3 \pm 3,39$ & $21,1 \pm 3,44$ & $20,4 \pm 2,57$ \\
\hline
\end{tabular}

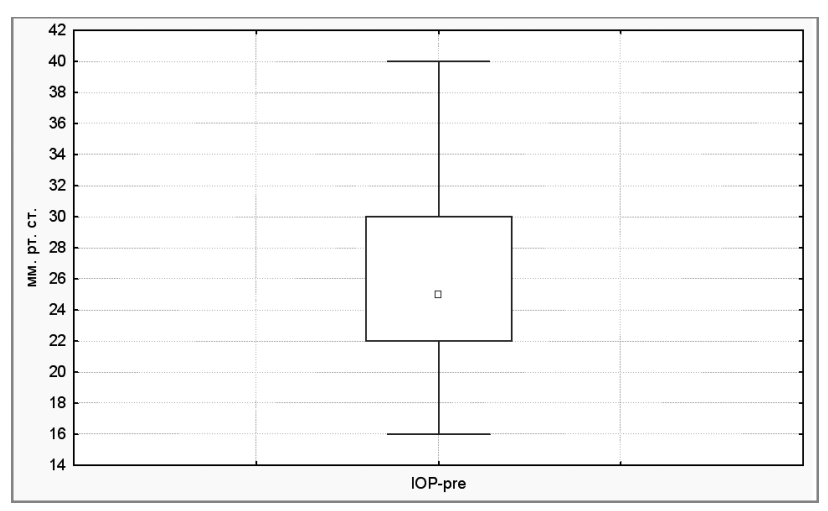

Рис. 1. Показатели внутриглазного давления до операции «ab interno» трабекулэктомии

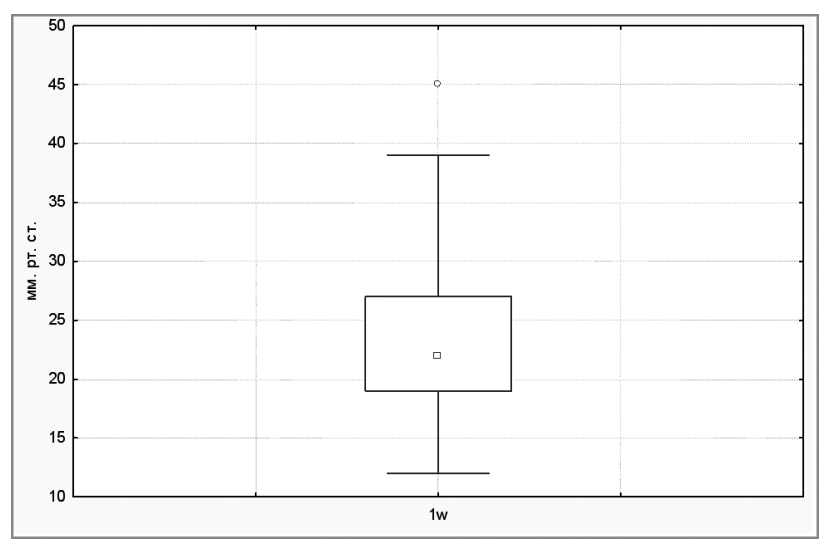

Рис. 2. Показатели внутриглазного давления через 1 неделю после «ab interno» трабекулэктомии

Динамика значений ВГД до 26 недель после операции изучена у 11 больных (11 глаз). Уже через две недели после операции отмечается снижение ВГД с 27,4 до 25,3 мм рт. ст. $(\mathrm{p}=0,00012)$, которое сохраняется в течение всего дальнейшего периода наблюдения за больными (рис. 3).

Во всех случаях операции протекали без осложнений. В первые часы после трабекулэктомии у 19 больных (24 глаза) отмечалось развитие гифемы, которая полностью рассосалась в течение одной недели. В трех случаях наблюдалось интраоперационное повышение ВГД во время выполнения трабекулэктомии, в связи с чем выполнение факоэмульсификации проводилось на следующий день. У одного больного $(1,6 \%)$ на одном глазу, вследствие ретро- 
градного поступления крови из эписклеральных вен в переднюю камеру и в стекловидное тело, развился гемофтальм, что потребовало проведения витрэктомии. У двух больных (2 глаза) (3,2\%) в связи с отсутствием полной нормализации ВГД и дальнейшим прогрессированием глаукомы была произведена повторная операция - глубокая непроникающая склерэктомия. В последующие сроки наблюдения ВГД у повторно прооперированных больных находилось в пределах нормы (табл. 1).

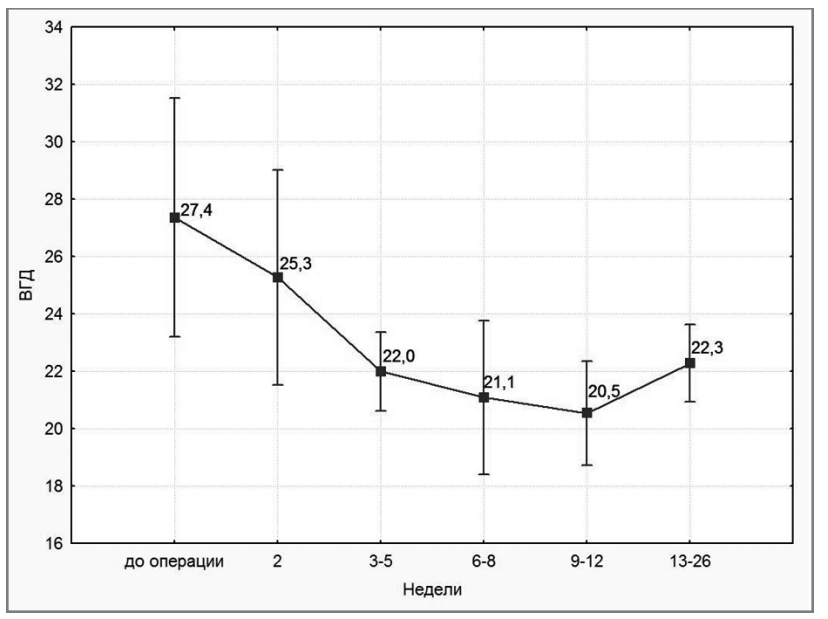

Рис. 3. Динамика показателей внутриглазного давления в течение 26 недель после «ab interno» трабекулэктомии

В результате проведенного лечения в исследуемой группе больных отмечалось повышение остроты зрения (по таблице Головина-Сивцева) с $(0,3 \pm 0,25)$ до $(0,57 \pm 0,33)$ через 6 месяцев после операции.

В таблице 4 представлены показатели ВГД до и после операции в зависимости от объема хирургического вмешательства. Вне зависимости от типа операции отмечается одинаковая тенденция к снижению ВГД на 20,7-23,8 \% в средние сроки наблюдения $(5,7 \pm 5,67)$ месяцев. Достоверной разницы между показателями ВГД после операции в сравниваемых группах не выявлено $(\mathrm{p}=0,22)$.

Таблица 4

Показатели ВГД (мм рт. ст.) до и после операции с использованием операционной системы «Trabectome» в зависимости от объема оперативного вмешательства $(\mathrm{M} \pm \mathrm{SD})$

\begin{tabular}{|l|c|c|}
\hline \multirow{2}{*}{ Оперативное вмешательство } & \multicolumn{2}{|c|}{ Внутриглазное давление } \\
\cline { 2 - 3 } & до операции & $\begin{array}{c}\text { после } \\
\text { операции }\end{array}$ \\
\hline ФакотрабекулэКтомия & $25,6 \pm 5,64$ & $20,3 \pm 2,93$ \\
\hline «Аb internо» трабекулэктомия & $28,5 \pm 5,06$ & $21,7 \pm 4,49$ \\
\hline
\end{tabular}

Заключение. Таким образом, применение «ab interno» трабекулэктомии с использованием операционной системы «Trabectome» позволило снизить ВГД у больных ПОУГ на 21,5\% в средние сроки наблюдения $(173 \pm 170,2)$ дней. Механизм гипотензивного действия этого вида операции связан с микроинвазивным удалением трабекулярной ткани, являющейся основной причиной сопротивления оттоку внутриглазной жидкости [14], что обосновывает выбор именно этого подхода к лечению больных открытоугольной глаукомой.

К преимуществу данного метода трабекулэктомии также необходимо отнести возможность одномоментного проведения факоэмульсификации через единый тоннельный разрез роговицы. Также обращает на себя внимание и минимальное количество осложнений в послеоперационном периоде по сравнению со стандартной методикой трабекулэктомии с интраоперационным применением антиметаболита митомицина С [7]. Удаление трабекулярной ткани через разрез роговицы под микроскопическим контролем с использованием прямой гониолинзы и операционной системы «Trabectome» происходит без операционной травмы конъюнктивы и склеры, что позволяет при необходимости провести антиглаукомную операцию по другой методике.

\section{ЛИТЕРАТУРА}

1. Алексеев Б. Н.// Проблемы катаракты / Алексеев Б. Н. - Куйбышев, 1975. - С.31-37.

2. Анисимова С. Ю. Актуальные проблемы хирургического лечения глаукомы / С. Ю. Анисимова, Осипов А. В. - М., 1989. - С. 34-38.

3. Козлов В. И. Непроникающая глубокая склерлимбэктомия с коллагеном / Козлов В. И., Багров С. Н., Анисимова С. Ю. и др.// Офтальмохирургия. - 1990. № 3. - C. 44-46.

4. Малюгин Б. Э. Современные технологии хирургии катаракты / Б. Э. Малюгин Б. Э., Г. Т. Джндоян. - М., 2000. - C.109-115.

5. Нарушения зрения и слепота // Информационный бюлетень. - 2011. - № 282.

6. Bindish R Efficacy and safety of mitomycin-C in primary trabeculectomy; five-year follow-up / Bindish R, Condon GP, Schlosser JD et al. // Ophthalmology. - 2002. № 109. - P. 1336-1341.

7. Brian A. Francis Combined cataract extraction and trabeculotomy by the internal approach for coexisting cataract and open-angle glaucoma: Initial results / Brian A. Francis, Don Minckler, Laurie Dustin et al. // J. Cataract Refract. Surg. - 2008. - Vol 34. - P. 1096-1102.

8. Brian A. Francis Novel Glaucoma Procedures, A Report by the American Academy of Ophthalmology / Brian A. Francis, Kuldev Singh, Shan C. Lin et al. // Ophthalmology. - 2011. - Vol 118. - P. 1466-1480.

9. DeBry PW Incidence of late-onset bleb-related complications following trabeculectomy with mitomycin / DeBry P. W., Perkins T. W., Heatley G. et al. // Arch. Ophthalmol. - 2002. - № 120. - P. 297-300.

10. Francis B. A. Ab interno trabeculectomy: development of a novel device (Trabectome) and surgery for open-angle glaucoma / Francis B. A., See R. F., Rao N. A. et al. // J. Glaucoma. - 2006. - № 15(1). - P.68-73.

11. Friedman D. S. Surgical strategies for coexisting glaucoma and cataract: an evidence based update / Friedman D. S., Jampel H. D., Lubomski L. H. et al. // Ophthalmology. 2002. — № 109. - P.1902-1915. 
12. http://eyeworld.ru/?q=node/231

13. Jampel $\mathbf{H}$ Effect of technique on intraocular pressure after combined cataract and glaucoma surgery: an evidence-based review. / Jampel H. D., Friedman D. S., Lubomski L. H. et al. // Ophthalmology. - 2002. - № 109. - P. 2215-2224.

14. Jessica L. M. Ab interno trabeculectomy: Outcomes in exfoliation versus primary open-angle glaucoma / Jessica L. M., Karim F. Damji, Michael C. Stiles // J. of Cataract \& Refractive surgery. - 2012. - Vol. 32. - № 2. - P.315-323.

15. Murthy S. K. Trabeculectomy and phacotrabeculectomy, with mitomycin-C, show similar two-year target IOP outcomes / Murthy SK, Damji KF, Pan Y et al. // Can. J. Ophthalmol. - 2006. - № 41(1). - P.51-59.

16. Shaffer R., Rasenthal G. Comparison of cataract incidence in normal and glaucomatous population // Amer. J. Ophthalmol. -1970 . - V. 69, N 3. - P. 368-370.
17. Resnikoff S. Global data on visual impairment in the year 2002 / Resnikoff S., Pascolini D., Etya'ale D. et al. // Bull. World Health Organization. - 2004. - № 82. - P. 844-851.

18. Soltau J. B. Risk factors for glaucoma filtering bleb infections / Soltau J. B., Rothman R. F., Budenz D. L. et al. // Arch Ophthalmol. - 2000. - № 118. - P.338-342.

19. Song A. Delayed-onset blebassociated endophthalmitis; clinical features and visual acuity outcomes / Song A., Scott I. U., Flynn H. W. Jr et al. // Ophthalmology. 2002. - № 109. - P. 985-991.

20. Tarek Shaarawy Glaucoma / Tarek Shaarawy, Mark B. Sherwood, Roger A. Hitchings et al. - Elsevier Limited. - Volume 2: Surgical Management. - 2009.

Поступила 13.04.2012

Рецензент ст. науч. сотр., к. М. Н. О. А. Перетягин

\title{
MODERN POSSIBILITIES OF «AB INTERNO»TRABECULECTOMY WITH THE USE OF THE OPER- ATING SYSTEM «TRABECTOME» IN PATIENTS WITH PRIMARY OPEN- ANGLE GLAUCOMA AND CATARACT
}

Dmitriev S. K., Dushenchuk T. V., Lazar Yu. M., Kondratyeva E. I.

Odessa, Ukraine

«Ab interno» trabeculectomy with the use of the operating system «Trabectome» allows to low IOP by $21.5 \%$ during the follow-up of $(173 \pm 170.2)$ days after surgery in patients with primary open-angle glaucoma. The mechanism of hypotensive effect of this type of operation is associated with microinvasive ablation of the trabecula tissue as the main cause for resistance to outflow of the intraocular fluid. The advantage of this surgical procedure is also possibility to use the same corneal incision for trabeculectomy and phacoemulsification.

УДК 617.741-004.1+617.7-007.681]-089-008.8-06+612.017.1

\section{ВЛИЯНИЕ ЦИТОКИНОВОГО ПРОФИЛЯ ВНУТРИГЛАЗНОЙ ЖИДКОСТИ У БОЛЬНЫХ ГЛАУКОМОЙ И КАТАРАКТОЙ НА ХАРАКТЕР И ЧАСТОТУ ПОСЛЕОПЕРАЦИОННЫХ ОСЛОЖНЕНИЙ}

\author{
К. П. Павлюченко, д. мед. Н., проф., С. Ю. Могилевский, д. мед. Н., проф., \\ С. В. Зяблицев, д. мед. н., проф., В. Хадри, асп.
}

Донецкий национальный медицинский университет им. М. Горького

\begin{abstract}
Під наглядом знаходилось 39 хворих (45 очей) з первинною відкритокутовою глаукомою I-IV стадії в сполученні з катарактою. Всім хворим було виконане двоетапне лікування, до якого входила факоемульсифікація катаракти з імплантацією гнучкої IОЛ (I етап) та селективна лазерна трабекулопластика (II етап), яку виконували через 4-5 тижнів після I етапу. Обов'язковою умовою була медикаментозна нормалізація внутрішньоочного тиску перед виконанням I етапу. В ході факоемульсифікаціі проводили забір внутрішньоочної рідини; в ній вивчали наявність та рівень цитокінів - фактору некрозу пухлини TNF- $\alpha$ та фактору росту фібробластів bFGF. Рівень TNF- $\alpha$ коливався від 1,11 до 140,55 пкг/мл и становив $(24,61 \pm 5,43)$ пкг/мл, bFGF - від 1,0до 12,54 пкг/мл и становив $(3,33 \pm 0,44)$ пкг/мл. Встановлений прямий кореляційний зв'язок між рівнем TNF- $\alpha$ і характером та частотою запальних післяопераційних ускладнень, між рівнем bFGF й характером і частотою рубцювання в куті передньої камери ока, а також рівнем внутрішньоочного тиску після I и II етапів двоетапного лікування.
\end{abstract}

Ключевые слова: первичная глаукома, катаракта, внутриглазная жидкость, цитокины, двухэтапное лечение, осложнения

Ключові слова: первинна глаукома, катаракта, внутрішньоочна рідина, цитокіни, двоетапне лікування, ускладнення.

() К. П. Павлюченко, С. Ю. Могилевский, С. В. Зяблицев, В. Хадри, 2012 